\title{
La representación de moros y cristianos de Matián (Cúllar, Granada). Una fiesta enterrada por el éxodo rural
}

The drama of Moors and Christians in Matián (Cúllar, Granada). A fiesta extinguished by rural exodus

\author{
Cristóbal Cabeza-Cáceres \\ Universidad Autónoma de Barcelona. \\ cristobal.cabeza@gmail.com
}

\author{
Miguel Ángel Martínez Pozo \\ Centro de Estudios Pedro Suárez. Universidad de Granada. \\ mampozo@hotmail.com
}

\begin{abstract}
RESUMEN
Este artículo estudia la fiesta y la representación de moros y cristianos en honor a san Antonio de Padua de Matián (Cúllar Granada), que dejó de celebrarse en 1962 a causa de la emigración en masa que vivió su población hacia la industrializada zona de Ibi (Alicante). Se dan algunos apuntes históricos sobre la aldea, el modo de vida de sus habitantes a mediados del siglo XX y el proceso de emigración que sufrieron para contextualizar y seguidamente analizar tanto a través de fuentes orales como documentales dicha fiesta y representación. En el análisis se muestran una serie de características propias de dicha representación y de su evolución, así como ciertas similitudes con otros textos de la zona, lo cual permite datar aproximadamente su origen.
\end{abstract}

\section{ABSTRACT}

This article studies the festival called Moors and Christians and the performance honouring Saint Anthony of Padua which took place in Matián (Cúllar, Granada, Spain) until 1962. The celebration stopped due to the massive migration towards Ibi (Alicante), a highly industrialized area. Some notes are provided about the history of the village, the way of life of its inhabitants during the decades of 1950-60 and the migration process. This helps to contextualize the festival and its theatric nature, which is subsequently analysed through oral and documentary sources. The study underlines a series of specific characteristics of the theatrical text, its evolution and certain similarities with other texts from the same area, allowing an approximate dating.

PALABRAS CLAVE

moros y cristianos | Cúllar | Granada | emigración rural | san Antonio de Padua | teatro popular

KEYWORDS

Moors and Christians | Granada | Cúllar | rural migration | Saint Anthony of Padua | popular theatre

\section{Introducción}

Los moros y cristianos son una representación festiva de las batallas que hubo entre ambos bandos durante la reconquista y tienen una especial importancia en los antiguos reinos de Granada, Murcia y Valencia. A diferencia de otras manifestaciones festivas, los moros y cristianos gozan de una buena salud y se puede decir que desde la entrada de la democracia su prestigio está en alza. Prueba de ello son los pueblos del Altiplano de Granada como Benamaurel, primera localidad donde se introdujo la influencia valenciana dándole un mayor empuje a la fiesta en sí; Cúllar, donde la recuperaron en los años 1980 tras más de cincuenta años sin celebrarse; y Zújar, donde se celebra la romería más importante de la comarca de Baza.

Sin embargo, la emigración rural de los años 1960 también enterró consigo muchas fiestas de moros y cristianos, que han quedado vivas ya solo en la memoria de los que fueron sus protagonistas y en las 
transcripciones de sus representaciones. Solo en la comarca de Baza, se tiene constancia de que se han dejado de celebrar en los núcleos rurales canileros de Los Olmos y Valcabra, y en los cullarenses de Pozo Iglesias y Matián, entre otros.

El objetivo del presente trabajo conjunto es, pues, abordar el estudio de una de dichas fiestas, la de Matián, cuya población emigró en masa hacia Ibi y sus pueblos limítrofes, una zona fuertemente industrializada en la comarca alicantina de Alcoy. En primer lugar, daremos algunos apuntes históricos sobre la aldea, el modo de vida de sus habitantes a mediados del siglo XX y el proceso de emigración que vivieron, para con ello contextualizar y seguidamente analizar -tanto a través de fuentes orales como documentales- la fiesta y la representación de moros y cristianos que se celebraba en honor a san Antonio de Padua. Finalmente, apuntaremos una serie de ideas como conclusiones de nuestro estudio.

\section{Matián, cortijada de Cúllar}

Matián es uno de los diecisiete núcleos de población reconocidos actualmente en el municipio de Cúllar (Granada), de cuyo núcleo urbano dista 12 kilómetros. Se halla en la zona suroriental del término municipal, a 1.080 metros de altitud y tan solo a cuatro kilómetros del límite con el término municipal de Oria (Almería). La aldea se sitúa en una planicie elevada junto a la rambla Bermeja, a dos kilómetros de la sierra del Madroñal y a cinco del alto de la Pililla $(1.331 \mathrm{~m})$. Se trata del núcleo poblacional cullarense más apartado de las principales vías de comunicación; de hecho el camino que lo une con las aldeas de Pulpite y de Venta Quemada -a 8 y 5 kilómetros respectivamente- sigue sin asfaltar y la luz eléctrica no se instaló hasta 1988. Todo ello influye en que sea uno de los núcleos con menos población, nueve personas censadas en 2011 según el Instituto Nacional de Estadística, y contribuyó al proceso de emigración que experimentó su población en la década de 1960, aunque realmente el factor clave de todo ello fue, y sigue siendo, la propiedad de la tierra y de las edificaciones.

Aunque Torices Abarca y Zorita Povedano (1994) proponen en un estudio para la Junta de Andalucía que el topónimo de Matián es de origen tardorromano, según el historiador cullarense Javier Castillo Fernández (1) este proviene del primer propietario que construyó en aquellas tierras un cortijo, como ocurre con los nombres de muchos otros cortijos de la zona; en este caso, Matián de Santiago, un escribano de Baza de mediados del siglo XVI.

Hasta el momento, la historia de la aldea aún está por estudiar, lo cual merecería un trabajo propio, aunque sí que hay algunos datos dispersos que ya han sido publicados. Por ejemplo, hay constancia de que en 1696, Bartolomé Marín de Poveda, clérigo de una poderosa familia del cercano Lúcar (Almería) que hizo las Américas, "hizo una de sus grandes inversiones al comprar una enorme finca de secano, conocida como el cortijo de Matián" (Andújar Castillo y Giménez Carrillo 2011: 207).

En el Catastro de Ensenada, realizado entre 1749 y 1759, se recoge que "ay un molino de biento en los cortijos de Mathian distante dos leguas de la población" (AGS: CE RG L281 FOL121). A finales del siglo XVIII, Matián ya debía de tener una cierta entidad en el sí del municipio, ya que el señor de Cúllar nombra en 1773 un diputado para el "Partido y Cortijada de Matián" (2). 


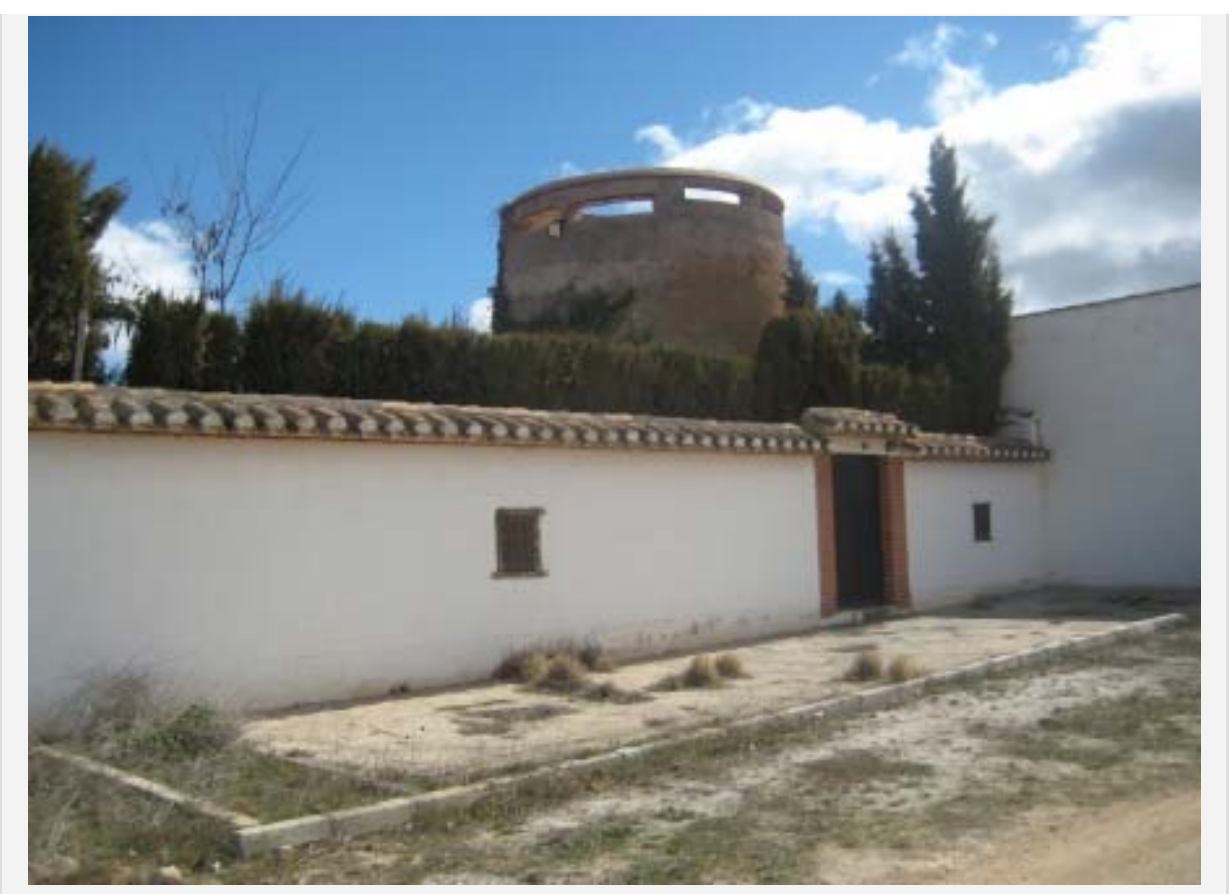

Figura 1. Estado del antiguo molino de viento (2012).

Ya en el siglo $X X$, los testimonios orales nos dan como propietarios del lugar una acaudalada familia granadina, los Sánchez-Reina -los señoritos-, que, si bien han ido vendiendo propiedades, siguen siendo los actuales propietarios de la mayor parte de edificaciones y tierras del lugar.

En el estudio nombrado anteriormente de la Junta de Andalucía se describe Matián como:

"una agrupación de construcciones distribuidas en torno a una vivienda principal y una torre defensiva (...) La estructura actual del asentamiento es abierta, organizada en dos núcleos: junto al camino se disponen en hilera las distintas unidades residenciales y productivas, al cobijo de la torre, y alejada de la aglomeración, a una cota inferior, se emplaza la ermita" (Torices Abarca y Zorita Povedano 1994: 1).

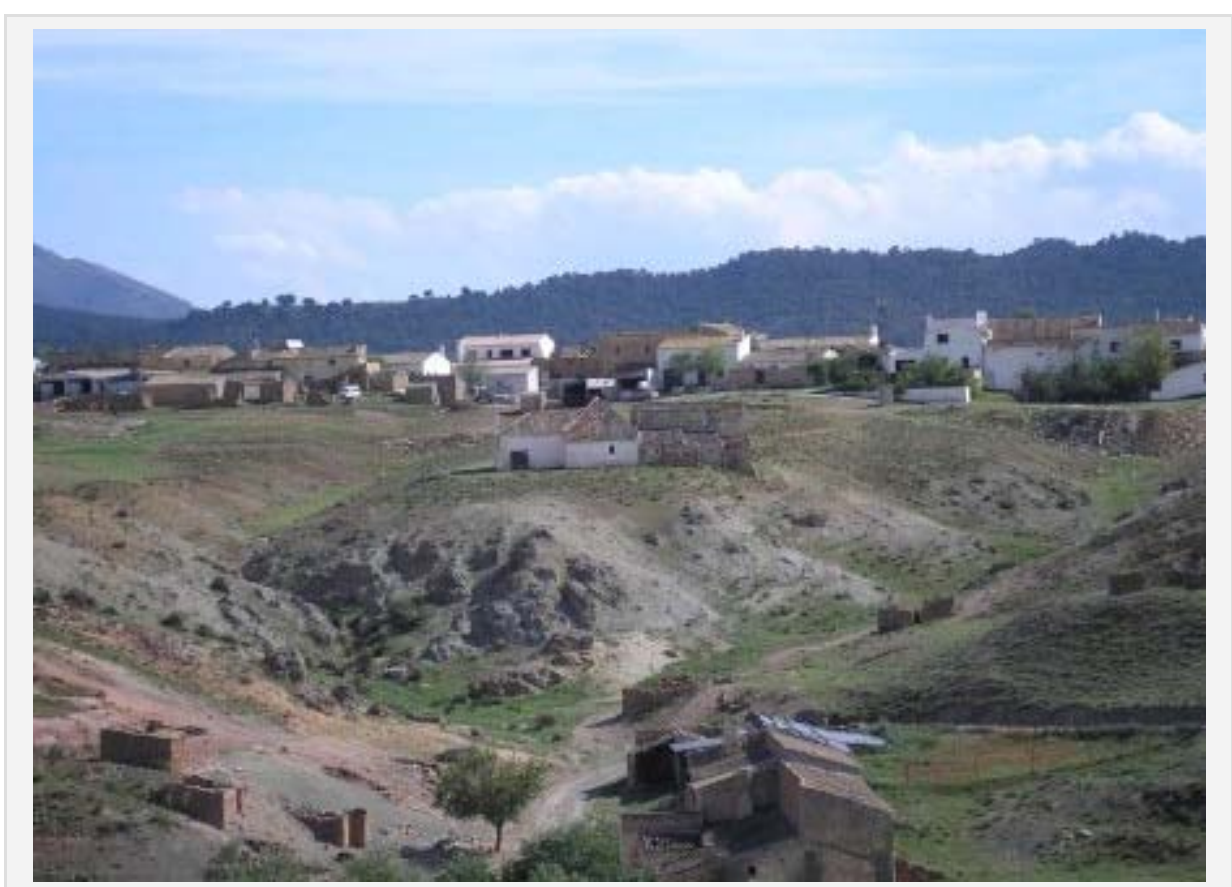

Figura 2. Vista parcial de Matián (2007). Fotografía de excavamatian: http://www.panoramio.com/user/2952882 
Creemos que dicha "torre defensiva" es en realidad el molino de viento recogido en el Catastro de Ensenada, único en la zona (Domene García y Rojas Sola 2001), aunque sería necesario un estudio arquitectónico para datarlo. Pensamos que es acertada la idea de que las edificaciones se construyeron alrededor de una casa matriz, el llamado granero o casa de los señoritos hoy todavía en pie aunque abandonado, que, según una inscripción en la fachada parece datar de 1742 (Torices Abarca y Zorita Povedano 1994: 1). Por lo tanto, la evolución urbanística del lugar debió partir de la construcción en medio de una gran propiedad de tierra del cortijo matriz a la progresiva construcción por parte de los sucesivos propietarios de más casas para dar cabida a la creciente mano de obra necesaria para cultivar las nuevas tierras que se roturaban con el paso de los años.

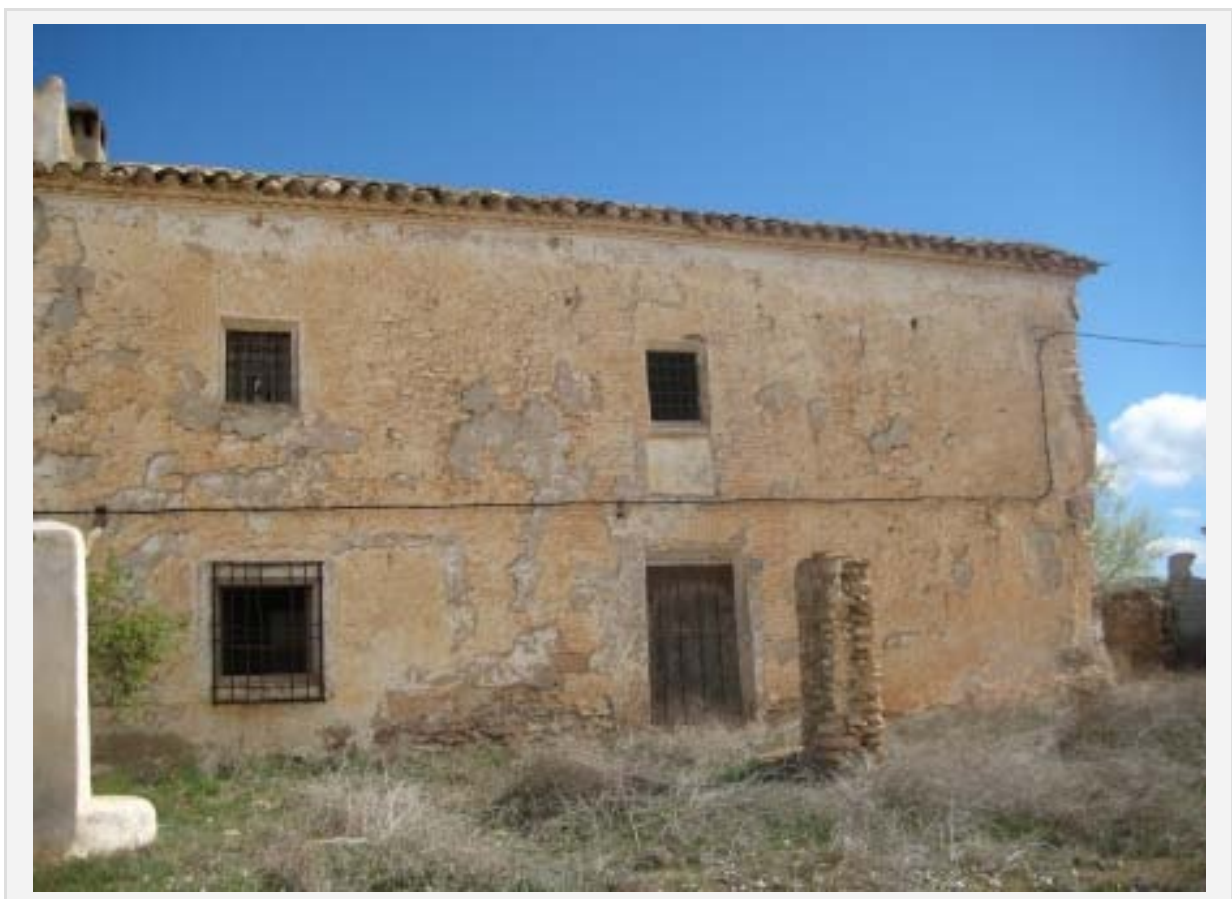

Figura 3. El granero o casa de los señoritos (2012).

Hay que decir que la propiedad de Matián no incluye solo el núcleo de población, sino una amplia llanura de cultivo a su alrededor de unos $20 \mathrm{~km} 2$, propiedad de los mismos dueños, que se dividía en quince labores de labranza de dos pares de mulos, las cuales en 1930 daban de comer a unas treinta familias, es decir, según el padrón municipal de Cúllar de ese año, a 189 personas (Valero Escandell 1999).

Esta concentración de tierras y viviendas bajo la propiedad de un único propietario explicaría que aún a mediados de siglo XX hubiera una relación de aparcería con prácticamente todos los habitantes del lugar, a pesar de su elevado número. Esta condición tan extrema -excepcional en el término de Cúllar, al menos en un territorio tan delimitado, agrupado bajo la propiedad de una única familia y reuniendo a tantas personas- podemos decir que condicionó parte de la idiosincrasia de la sociedad matianera como colectivo, tal y como veremos seguidamente.

\subsection{La sociedad matianera}

El hecho de que prácticamente ningún matianero fuera dueño de sus casas ni de las tierras que cultivaba hacía que todos se consideraran como iguales. En otras aldeas cullarenses como la cercana Venta Quemada, con la que Matián mantenía una estrecha relación, había pobres, que eran en muchas ocasiones propietarios de sus casas e incluso de alguna suerte -terreno de secano- o bancal -terreno de regadío-, y ricos, propietarios de grandes extensiones y de cortijos, los cuales vivían en la propia aldea. 
Sin embargo, bajo esta concepción social de la época, en Matián no había ricos, sino una única familia de señoritos, que residían en Granada y que solo pasaban en Matián la época estival.

Los señoritos designaban a un encargado, que era la persona que gestionaba todos los asuntos entre ellos y la población, además de recoger los quintos -en realidad cuartos-, que era el pago en grano que los labradores daban a estos por el cultivo de las tierras (trigo, cebada y centeno en el secano y verduras, yeros o leguminosas para el consumo propio en la pequeña zona de huerta junto a la rambla) y el uso de las casas. Además, existía la figura del guarda y del alcalde pedáneo, que podía coincidir o no con la de encargado.

En cuanto a la población, Valero Escandell (1994) observa una llamativa atracción hacia a la aldea de habitantes nacidos fuera de Cúllar en el primer cuarto de siglo XX, ya que apunta que en 1930 la población de aldea era en un 21,4\% foránea, en el $80 \%$ de los casos nacidos en la provincia de Almería. Las fuentes orales de los matianeros más ancianos confirman que muchos ancestros suyos provenían del limítrofe término municipal de Oria, donde la mayoría tiene familia lejana.

Además, hasta que se produjo el fenómeno migratorio, la aldea ejercía de "capital" de la docena larga de cortijos que había a su alrededor, algunos con varias familias y con hasta 20 o 30 habitantes, como los cortijos de la Bermeja, el Madroñal, la Casa del Abad, la Pililla o los Pinos, y tenía influencia sobre otros más alejados como el Saúco o el Colorado, algo que, como veremos más adelante, se refleja en los textos de la representación de los moros y cristianos.

No en vano, dichos cortijos pertenecían a la iglesia de Matián que, con su cementerio -ambos propiedad también de los señoritos-, se erigieron en parroquia independiente en 1928 (3) y contó con cura propio hasta la Guerra Civil. También contaba Matián con escuela, la cual, según Valero Escandell (1994, 1999), empezó a funcionar seguramente en la Segunda República. Además, muchos cortijeros iban a Matián en busca de los pocos servicios que ofrecía: en las décadas de 1950 y 1960 Matián contaba con un molino de harina -diferente del de viento, que ya estaba en ruinas-, dos tiendas-taberna y una posada, que daba alojamiento a los marchantes que se acercaban a la aldea a comprar o vender productos (Valero Escandell 1994, 1999). Las edificaciones que alojaban dichos servicios eran, precisamente, las únicas de propiedad diferente a la de los señoritos, y sus propietarios los únicos que tenían una actividad desligada del cultivo directo de la tierra. No es de extrañar, pues, como veremos más adelante, que algunos de los miembros de dichas familias jugaran un papel importante en la organización y la representación de los moros y cristianos y en la vida lúdica de la aldea.

En aquella sociedad rural, los cambios de vivienda entre la aldea y los cortijos eran frecuentes, ya fuera por trabajo o por casamientos; sin embargo, desde 1930 en adelante se observa un estancamiento y un ensimismamiento de la población, ya que en 1960 solo había en la aldea de Matián un 12,8\% de habitantes nacidos fuera de Cúllar (Valero Escandell 1994, 1999). Los testimonios orales nos confirman que desde que acabó la Guerra Civil hasta que empezó la emigración en los 60 prácticamente no hubo cambios en las familias que habitaban Matián.

Aunque en esas dos décadas España vivía las políticas económicas autárquicas del régimen franquista, se podría decir que no afectaron demasiado el modo de vida de Matián, ya que este había evolucionado bien poco en varios siglos. Se trataba de una economía de autoconsumo con muy pocos intercambios con el exterior y con unas condiciones de vida extremas, no solo por el clima continental de la zona: por ejemplo, los matianeros tenían que desplazarse diariamente a por agua a casi dos kilómetros de distancia; los suelos y muchos tejados eran de tierra; y ni que decir tiene que no se contaba con electricidad, que llegó a la aldea en 1988 (Valero Escandell y Monleón 1992).

Los trabajos sobre Matián de Valero Escandell (1994, 1999), basados en los trabajos y el documental de Valero Escandell y Monleón (1992) y hechos a partir de entrevistas a matianeros emigrados, y de García Gea (2010) sobre Chirivel, Cúllar, Oria y Los Vélez nos muestran con todo tipo de detalle la sociedad rural de la zona a mediados de siglo XX; por ello, no redundaremos en su descripción. Sin embargo, 
creemos que para contextualizar la fiesta de moros y cristianos que se celebraba en Matián sí que es interesante desarrollar con más detalle cómo aquella sociedad tan empobrecida económicamente disfrutaba, se divertía y pasaba sus momentos lúdicos.

Como en toda aquella zona, especialmente en las aldeas o cortijadas, hasta mediados de la década de 1960, la principal manera de divertirse los jóvenes era el baile. Normalmente lo organizaban los domingos los mozos, que pedían a alguien si podían hacerlo en su casa -se buscaban las más grandes, como por ejemplo la posada- y luego se convidaba a la mozas de la aldea y de los cortijos, que solían ir acompañadas de una madre o una abuela para controlar que no se violaran las normas sociales de la época. Sacar a una moza a bailar era una manera de entablar relaciones y de establecer contacto para un posible futuro noviazgo.

Hasta la década de 1960 se bailaba principalmente baile suelto (fandangos, seguidillas y jotas, en menor medida), pero a partir de entonces el baile agarrado (pasodobles, mazurcas, tangos, chotis o polcas) empezó a suplantar el primero. Aunque estos bailes se organizaban durante todo el año eran especialmente importantes en la época de la Pascua (Navidad), cuando Las Ánimas, la cuadrilla de músicos, recorrían las casas y los cortijos recogiendo el aguilando, una limosna para las Ánimas Benditas del Purgatorio que donaban a la Iglesia. Este tipo de agrupación es común a una gran zona que abarca el norte de las provincias de Granada y de Almería, el sur de Albacete y la Región de Murcia.

Como explica Tomás Loba (2008: 54) en un artículo en el que analiza estas formaciones tradicionales, "zonas o pequeños núcleos de población carentes de una Hermandad religiosa (...) han contado con una forma alternativa de 'gobierno' para las festividades. Es aquí donde aparece ante nosotros la figura del mayordomo". Según las fuentes orales, por ese nombre se conocía también en Matián a la persona que organizaba Las Ánimas, Lorenzo Miras, el tío Lorenzo el del Molino, uno de los pocos matianeros con propiedades a parte de los señoritos, en este caso el molino harinero que había en la rambla Bermeja, hoy totalmente derruido.

El cometido del mayordomo era "buscar músicos, una rondalla o cuadrilla para realizar la Carrera de Pascuas o Aguilandos por tiempo de Navidad [y] organizar las fiestas patronales propias de la advocación a la que estaba dedicada la ermita" (Tomás Loba 2008: 54-55), lo cual se confirma en Matián, ya que, como veremos en el apartado 3.2.2., el tío Lorenzo el del Molino era también quien se ocupaba de la representación de los moros y cristianos en honor a san Antonio.

De hecho, se puede decir que en Matián había una correlación bastante cercana entre la Cuadrilla de Ánimas y las personas que participaban en la representación de moros y cristianos: Antonio, hijo del tío Lorenzo, que tocaba el violín; Marcos Galera, que tocaba el laúd y que era guarda de Matián y de la familia que poseía la posada; y el tío Benito Carrión, propietario de una de las tiendas-taberna, que tocaba la guitarra, representaban también papeles importantes en los moros y cristianos.

Vemos así cómo los miembros de las familias dueñas de alguna propiedad en Matián, aún sin ser ricos y ser considerados como iguales por su conciudadanos, tenían un cierto papel social en la organización de los eventos ludicofestivos de la aldea, quizá también por disponer de más tiempo, tanto en el caso de aprender a tocar algún instrumento como para ensayar la representación de moros y cristianos.

\subsection{La emigración hacia Ibi}

La sociedad que acabamos de caracterizar se empezó a difuminar en 1963, cuando la primera familia matianera emigró hacia la zona de Ibi: si en 1930 Matián contaba con 189 habitantes, en 1965, en pleno proceso migratorio, contaba con 78 y en 1975 había ya solo 22 personas censadas:

"Para un éxodo tan radical fue necesaria la coincidencia de muchos factores de repulsión en 
origen y de atracción en destino. El primero de ellos, la situación social explosiva que se vivía en la aldea: la falta de acceso a la propiedad de la tierra, las dificultades inherentes a una economía de cuasiautoconsumo, los bajos ingresos que impedían acceder a bienes que se estaban generalizando en la sociedad española, las profundas deficiencias en servicios básicos (sanidad, educación, transporte) y la carencia de infraestructuras imprescindibles: agua, electricidad, caminos asfaltados, viviendas dignas. Además, el convencimiento de que aquel mundo no tenía futuro para sus hijos, en una época en que la educación y el trabajo industrial se consideraban como un medio de ascenso social" (Valero Escandell 1994: 2).

Aquellos matianeros emigrados se fueron integrando y fueron aportando a la sociedad ibense, que en aquellos mismos años, desde 1960 a 1975, cuadruplicó su población con gente de la misma zona, pero también de otras de la Mancha o de Jaén. El hecho de que familias enteras -entendidas como grupo de padres e hijos y de todos o casi todos sus hermanos y sobrinos- emigraran a lbi y de que no se dispusiera de casa en propiedad en Matián hizo que el contacto posterior con la aldea fuera mínimo.

Además, el hecho de que mucha otra gente de Cúllar y de sus aldeas también emigrara a Ibi (en 1981 había censados más de un millar de personas nacidas en su término (Valero Escandell 1999)) disolvió el origen matianero en favor del cullarense y, aunque a día de hoy, sobre todo los más mayores siguen manteniendo los vínculos entre ellos, la cultura propia del lugar quedó relegada a un rincón de la memoria. En parte, este artículo lo que pretende es evitar el olvido de aquella cultura, dignificarla y darle el lugar que merece.

\section{Fiestas de moros y cristianos en Matián en honor a san Antonio de Padua}

Atendiendo al historiador jienense Fernández Hervás (1992), la primera victoria cristiana obtenida por don Pelayo en Covadonga, donde la santísima Virgen tuvo una especial intervención, y la ayuda que el apóstol Santiago prestó en la batalla de Clavijo, marcarán el sentimiento religioso de las fiestas de moros y cristianos, aunque hay que admitir que en un principio tuvieron un origen caballeresco.

"Representaciones teatrales, lidias ecuestres y bailes de espadas... son distintas formas de actuaciones que, designadas como moresmas, morismas, soldadescas, moros y cristianos, danzas, entre otras, se han celebrado desde la Edad Media hasta hoy día en nuestro país, España, así como en otros. Es conocida, como la más antigua, la celebrada en Lérida en el año 1150, con motivo de la boda entre Petronila de Aragón y Ramón Berenguer IV aunque, según otros historiadores, podríamos encontrar indicios en el Cantar del mío Cid. En los siglos sucesivos este tipo de celebraciones se fueron extendiendo por todo el territorio nacional, siendo a partir del S. XVI, coincidiendo con la reconquista de Granada, cuando comenzaron a tener mayor auge" (Martínez Pozo 2008: 90-91).

Episodios históricos posteriores, tales como la constante lucha con el Imperio Turco por el dominio del mar Mediterráneo durante el siglo XVI, la sublevación de los moriscos y su expulsión, la guerra de la Independencia así como la guerra de África propiciaron este tipo de fiestas en numerosas poblaciones de toda España. Todo ello llevó a numerosos dramaturgos a tomar como escenario de sus obras las distintas luchas entre los bandos.

Tal y como expresa Fernández Hervás (1992), en el siglo XVII se introduce la costumbre de solemnizar la fiesta del santo patrón del pueblo o ciudad, con simulacros de moros y cristianos, como son el caso de Caudete (Albacete) en 1617, Alcoy (Alicante) en 1688 y, en la provincia de Granada, Orce en 1639.

Allá por el siglo XVIII, este tipo de fiestas poseen una gran importancia, pero durante el reinado de Carlos III muchas desaparecen debido a la promulgación de leyes que prohíben la representación de autos sacramentales (Real Cédula de 11 de junio de 1765), ordenan la disolución de cofradías (Real 
Cédula de 16 de 1776) y censuran todos los bailes y representaciones en procesiones y atrios de las iglesias. Aquellas de las que se tiene constancia documental que sobrevivieron, como fue el caso de Benamaurel y Zújar en la comarca de Baza, se fortalecieron e intensificaron, con lo que congregaban a numerosos visitantes y se hicieron conocidas y renombradas en décadas posteriores.

Ya en el siglo XIX, el Romanticismo trajo consigo el amor a lo popular y a las tradiciones caballerescas cristianas. Ello y la toma de Tetuán por el ejército español en 1860 propició que en muchas poblaciones se adaptaran fragmentos de comedias o relaciones en verso anteriores o se realizaron unas nuevas en forma de representación de moros y cristianos como, por ejemplo, Benínar. En otras poblaciones utilizaron versos y textos de localidades colindantes para crear las suyas propias, algo perfectamente entendible en un contexto de intercambio cultural entre poblaciones vecinas, por ejemplo, Cúllar.

Aunque existió nuevamente un período de decadencia y pérdida de las representaciones antes y durante la Guerra Civil, en numerosas poblaciones con la llegada de la transición Española se recuperan o se crean, tomando gran auge por el gran empuje económico y turístico que estas ocasionan en aquellas localidades que las celebran.

En cuanto a estudios sobre estas fiestas, a pesar de existir diferentes citas durante el siglo XIX y principios del XX sobre Granada, el arranque surgió poco después de la Guerra Civil, cuando Guastavino Gallent, siguiendo el precedente de otros africanistas, decide recopilar de la tradición oral una de las representaciones alpujarreñas. El espaldarazo internacional casi definitivo vino de la pluma de Marcel Bataillon en 1949, al publicar el artículo "Por un inventario de las fiestas de moros y cristianos: otro toque de atención" (Brisset 1988: 27). A partir de entonces numerosas publicaciones salieron a la luz con un mismo objetivo: el conocimiento de este tipo de fiestas en la provincia de Granada.

\subsection{Las fiestas de moros y cristianos en la comarca de Baza}

La referencia más antigua dentro de la comarca de Baza sobre algún tipo de representación de moros y cristianos se debe a la fiesta celebrada en Baza por la segunda venida a España de Carlos I y $\mathrm{V}$ de Alemania tras la victoria sobre los comuneros y su nombramiento como emperador del Imperio Alemán (Martínez Pozo 2008: 107). En actas del Cabildo de Baza del 1 de agosto de 1522, textualmente nos dice:

"Otros y hordenaron e mandaron lo dichos señores que para las fiestas que se an de hacer el domingo por la fiestas e alegrías de sus Majestades que se haga un castillo de madera para que se combata de moros y cristiano e que por ello para hazello mande a los carpinteros tenga cargo el señor teniente (de alcalde) e Hernando de Cuenca, jurado".

Baza, Benamaurel, Caniles, Cortes de Baza, Cúllar y Zújar, así como aldeas o anejos de estas poblaciones, contaron en algún período de su historia con representaciones que festejaban y realizaban en honor a su santo patrón o patrona (4).

Son de destacar las fiestas de moros y cristianos en las localidades de Benamaurel y Zújar por su antigüedad e importancia cultural, histórica, literaria y antropológica, y la población de Cúllar, ya que es, dentro de la comarca de Baza junto con Caniles, la que cuenta con un mayor número de representaciones.

Benamaurel y Zújar. Sus primeras representaciones pertenecen a las comedias de "moros y cristianos" que se realizan desde los siglos XVI-XVII en las poblaciones donde "el elemento tradicional de los autos -lucha del Mal contra el Bien, simbolizados en el Demonio y el Ángel- se unía el más nuevo y en consonancia con los tiempos, la lucha contra la Berbería" (Martínez Pozo 2008: 110). El hallazgo de sus representaciones primitivas verifica, de acuerdo con el análisis de su contenido, que éstas fueron 
En la actualidad, ambas poblaciones poseen un texto único, diferente del primitivo, denominado Cautiverio y rescate de nuestra señora de la Cabeza y conocido popularmente como "los papeles", cuyo manuscrito más antiguo conservado data del año 1835, el cual se halla en Zújar y podría tratarse del original llegado años e incluso décadas antes. Benamaurel lo adoptaría para su representación, dentro de su núcleo urbano, puesto que ambas localidades celebraron conjuntamente desde el siglo XVI hasta las primeras décadas del XIX la subida al cerro Jabalcón (6), siendo en la actualidad, junto con la devoción a la Virgen de la Cabeza, nexo de unión entre ambas poblaciones.

Una especial mención merece este auto sacramental, ya que el autor (anónimo) demuestra conocer las obras teatrales del Siglo de Oro de la literatura española, apreciándose influencias del teatro de Calderón de la Barca e imitación de tópicos de Lope de Vega y viéndose en él a un dramaturgo profesional. Esta representación se considera por algunos investigadores como la fiesta de moros y cristianos de más valor literario de cuantas se celebran en España (7). Celebradas el último fin de semana de abril, desde el viernes hasta el martes siguiente, son unas fiestas que congregan a multitud de visitantes y están consideradas de Interés Turístico, Patrimonio Inmaterial de Andalucía y Huella del Milenio del Reino de Granada (Martínez Pozo, 2012: 151-179).

Cúllar. La localidad de Cúllar es una de las poblaciones que cuenta con más representaciones de moros y cristianos en la comarca de Baza, unas vigentes y otras desaparecidas por el éxodo de sus habitantes o porque dejó de celebrarse la festividad al patrón a quien iban dirigidas. Resumidamente cuenta con:

Representación en honor a san Sebastián (no vigente).

El primer documento del que tenemos constancia que cite esta representación es un artículo publicado en el periódico El Defensor de Granada el día 12 de febrero de 1884, n 121, así como de la entrega de pólvora por parte de la hermandad para celebrar otra representación, la de la Virgen de la Cabeza, a principios del siglo XX.

Atendiendo al manuscrito analizado, según la grafía, escritura y términos utilizados, data de finales del siglo XIX o principios del XX. Posiblemente se trate de una adaptación del original que estuviera en mal estado de conservación (Martínez Pozo 2009:140-167). Se consideran las fiestas de moros y cristianos más antiguas de esta localidad, tratándose de una embajada o "escaramuza de castillo".

Representación en honor a nuestra señora de la Cabeza (vigente).

La actual representación data del año 1898, cuyo texto fue aprobado junto con las Ordenanzas $y$ constituciones por las que se han de guiar los hermanos de santa María de la Cabeza de Cúllar-Baza y es una fiel adaptación de los primitivos de Benamaurel (Martínez Pozo 2008) que habían caído en desuso. Se cree que las fiestas se dejan de realizar con motivo de un disparo fortuito que dio la muerte a Pantaleón Fernández Escudero en 1927. Sin embargo, el recuerdo de la misma y su persistencia en los pueblos cercanos de Benamaurel (donde algunos cullarenses desfilaban en la escuadra moros del Haufí) y Zújar hicieron que un grupo de jóvenes la recuperaran en 1983 (8). Su representación, conservada por un vecino, sale a la luz en 1987 gracias al maestro Juan de Dios Villanueva Roa (9) escenificándose, desde entonces, en las escalinatas que dan acceso al templo parroquial (10).

Aunque su texto no ha sido publicado, Torres cita un documento sin fechar "idéntico al de Zújar y Benamaurel" (Torres 2010: 62) de Cautiverio y rescate de nuestra señora de la Cabeza con anotaciones sobre los años, supuestamente, de celebración de la representación a partir de 1871 verificándose la investigación realizada por Martínez Pozo (2008, 2010). Este hecho se da en otras poblaciones cercanas, como Bácor-Olivar, Cogollos de Guadix o Las Juntas donde existen copias de finales del siglo XIX adaptadas a la toponimia del lugar, tal y como ocurre en Cúllar, circunstancia dada por la importancia que tuvo este auto sacramental en las fiestas de Benamaurel y Zújar en dicho siglo ypor acontecimientos históricos que hicieron resurgir o nacer esta fiesta en diferentes poblaciones o aldeas. 
Representación a san Torcuato en Pozo Iglesias (no vigente).

Se trata de una embajada propia de la aldea cullarense de Pozo Iglesias. Su manuscrito está fechado en 11 de abril de 1902 y firmado don Luis Blánquez Vel. Sus personajes son general moro (Mojamé), embajador moro (Hebaín), general cristiano (conde de Luna, gobernador de Almanzora), embajador cristiano (capitán Pizarro), Celín y las intervenciones sobrenaturales de Luzbel y del ángel (11).

Representación a san Antonio en Matián (no vigente).

Se trata de la representación objeto de nuestro estudio, la cual ha sido recogida y analizada brevemente por Castillo Fernández (2008) y Torres Jaraba (2010). Con nuestro trabajo pretendemos ampliar el conocimiento y aportar nuevos datos sobre dicha representación, lo cual pasamos a realizar seguidamente.

\subsection{Las fiestas de moros y cristianos en Matián}

San Antonio de Padua, también venerado como san Antonio de Lisboa (Lisboa, 15 de agosto de 1195 Padua, 13 de junio de 1231), fue un monje, predicador y teólogo portugués. La devoción antoniana, cuya fiesta se celebra el 13 de junio, es una de las expresiones más significativas de la piedad popular y está muy extendida en toda la comarca de Baza y en la vecina de Los Vélez, donde existen numerosas ermitas (como en Benamaurel, Caniles, El Piar (Vélez-Blanco) o El Contador (Chirivel).

Atendiendo al diccionario geográfico-estadístico-histórico de España y sus posesiones de ultramar por Pascual Madoz (1845-1850), al hablar de Cúllar nos especifica:

"Cúllar de Baza. Iglesia parroquial (Nuestra Señora de la Anunciación) curato de término: 4 ermitas en la población destinadas a san Agustín, san José, san Antonio, Ángel de la Guarda, y 5 en el campo, en las aldeas o casas siguientes: en las Vertientes (san Juan); Barrio-Nuevo (san Antonio); el Margen (La Concepción); Matián (san Antonio); y la 5a en Pozo Iglesias".

Por lo tanto, al menos desde mediados de siglo XIX la advocación de la ermita de Matián es a san Antonio de Padua, aunque hay constancia de que en 1716 la advocación era a la Virgen del Rosario (AGA, Zapata, 4973.2). La ermita, que los matianeros consideraban iglesia, ya que fue parroquia independiente desde 1928 hasta 1975 (Valero Escandell 1999) es un edificio protegido por las normas subsidiarias de Cúllar de 1999. El estudio sobre la aldea realizado para la Junta de Andalucía la describe así:

"La ermita es una sencilla construcción rectangular, adosada a una vivienda [ya inexistente], que consta de dos volúmenes, el de la nave y el de la capilla mayor, cubierta a cuatro aguas. A los pies se dispone la fachada principal, rematada por una espadaña afrontada descentrada, en que se abre una portada adintelada sobre la que se exhibe un elemento heráldico. El escudo nobiliario probablemente corresponda con el patronazgo de la ermita. Circular, está timbrado con un yelmo con lambrequines y su campo está cortado en dos" (Torices Abarca y Zorita Povedano 1994: 1).

Según el testimonio de la familia Galera Reche, la actual imagen de san Antonio, junto con la Virgen de Fátima, la Purísima y Jesús Crucificado (las cuales se encuentran en la ermita) fueron compradas tras la Guerra Civil con la recaudación obtenida durante el ciclo festivo matianero de Navidad a través de la cuadrilla de las ánimas. Según esta familia, solo una imagen, el Sagrado Corazón de Jesús, fue donada por don Miguel, propietario y terrateniente de la cortijada, perteneciente a la familia de los Gómez Sánchez-Reina.

En cuanto a la representación de moros y cristianos en dicha cortijada, se carece de documentación escrita que verifique el año en el que empezó a realizarse. Por lo tanto, solo queda el testimonio oral de 


\subsubsection{El día de san Antonio}

El 13 de junio era el día más importante del ciclo festivo matianero, en el cual se celebraba san Antonio, el santo patrón de la aldea. Era día de estrenar ropa quien podía y también cita obligada para los cortijeros, que acudían a la cortijada a celebrar la festividad. Hay que tener en cuenta que dicho día caía justo en medio de la época de siega, por lo que las gentes solo guardaban el día de la celebración y se reincorporaban enseguida a las labores del campo habiendo incluso quien, por no ser joven y tener tareas del hogar o del campo, solo iba a misa y no asistía a la representación de los moros y cristianos.

Por la mañana, después del repique de campanas, comenzaba la santa misa. Posteriormente se realizaba la procesión, que recorría las calles de la aldea. Cuando se llegaba delante de la posada, en el camino que había delante de la aldea llamado el Rulador porque allí se jugaba a rular la bola, junto a uno de los pocos almendros que había en la zona se colocaba al santo. Previamente se la había preparado a modo de altar una mesa enramada con ramas de álamo por algunos mozos y los vecinos se distribuían alrededor de ella, en círculo, sentándose en los poyetes o en el suelo. Entonces comenzaba la representación de los moros y cristianos: con gran maestría y elegancia, ataviados con las ropas para la ocasión, entraban en caballos y mulas los papelistas, que representaban la "primera parte".

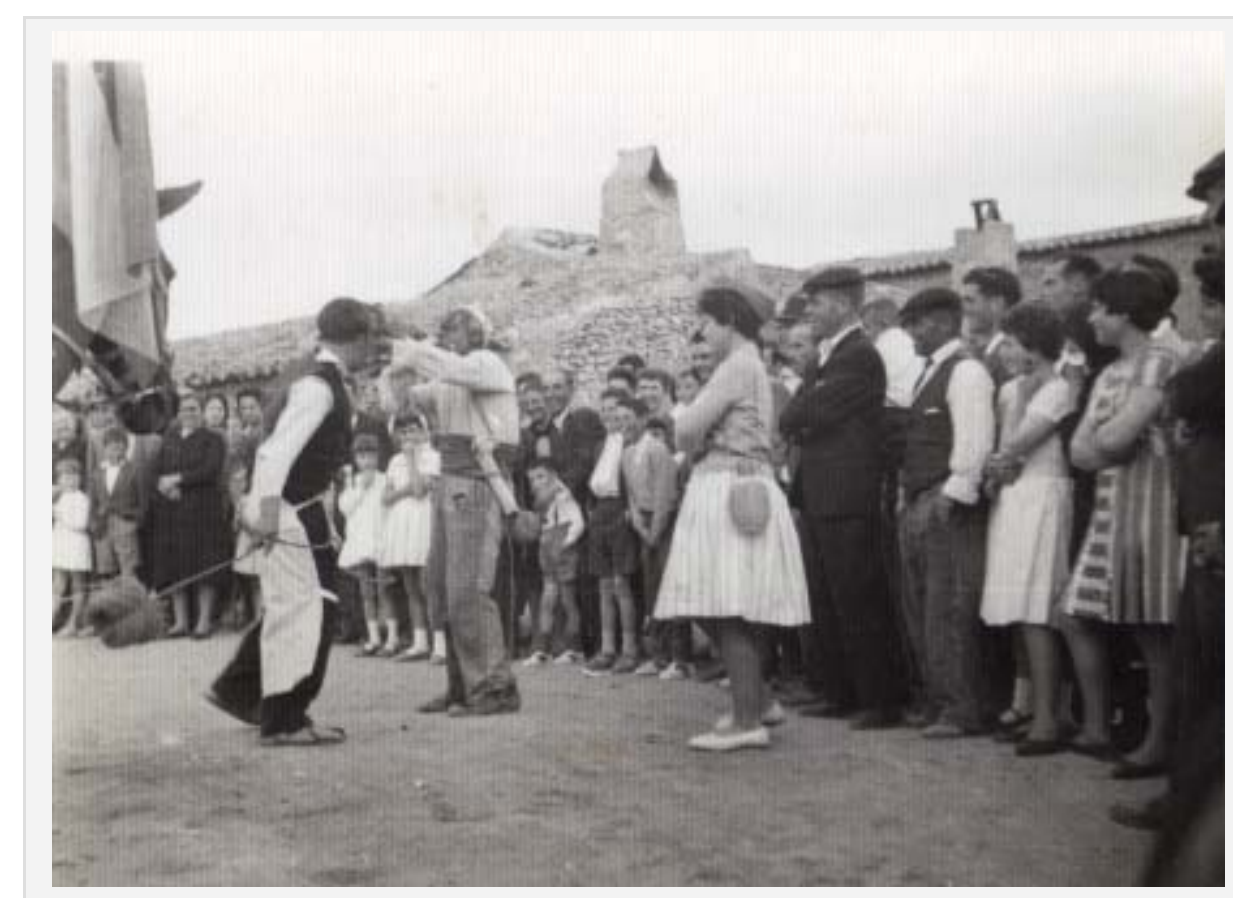

Figura 4. Momento de la representación (1962). De izquierda a derecha: una mula, la bandera, Luzbel, un espía y la cantinera cristiana.

Una vez finalizada, los moros portaban al santo hasta la ermita, donde aguardaba hasta las tres de la tarde mientras los matianeros comían en sus casas. Aquel día se cambiaban las repetitivas migas y ollas por el plato de fiesta, el arroz seco. También había quién mataba un pollo, que normalmente se vendían en el mercado de Cúllar para sacar un dinero extra, o quien abría un bote de conserva y hacía fritá de tomate y pimiento como algo excepcional. Cuenta Gregoria Fernández Carrión que el último año que se celebró la fiesta, 1962, el encargado de los señoritos invitó a comer en el granero por voluntad de estos a todos los participantes en la representación y en la organización de la fiesta, como los que montaron el altar. Cabe decir que los señoritos no asistían a las fiestas, ya que aún no habían llegado a la cortijada para pasar la época estival. 
Por la tarde, el santo era trasladado por los moros nuevamente hasta la posada, donde se escenificaba la "segunda parte". Una vez vencidos por los cristianos, estos lo llevaban nuevamente a la ermita y se lanzaba algún que otro cohete. Cuenta Marcos Galera Reche que, por la tarde, pujaban los mozos para entrar a san Antonio a la ermita. Quienes más pujaban se encargaban de organizar la fiesta al año siguiente, tradición conservada en otras localidades cercanas como Caniles (Díaz Sánchez 2012) o el anejo de Fátima perteneciente a Castril de la Peña.

Al acabar la representación, los jóvenes comenzaban lo que se llamaba el paseo, que consistía en recorrer las calles en cuadrilla. Según cuenta Pilar Fernández Reche, para entonces, si no antes, ya habían llegado andando, en mula o en burra, los mozos y mozas de los cortijos de la Bermeja, La Casa del Abad, El Madroñal, Los Pinos, La Pililla, Los Cortijillos, Los Muñoz, Malagón, Don Pedro, Santa Olalla, EI Saúco, La Hinojora y de las aldeas de alrededor como Venta Quemada y Pulpite, siendo pocos los que venían de otras cortijadas o de los núcleos de Cúllar o de Oria, a no ser que tuvieran algún familiar. En el paseo se conocían, hablaban y surgían en ocasiones parejas, haciéndose así realidad los ruegos que muchos jóvenes hacían por tradición a san Antonio, encomendándose a él para encontrar pareja. Según Gregoria Fernández Carrión, era también el momento de comprarse un helado o un trozo de turrón de los dos únicos puestos que venían de Cúllar y de Oria respectivamente.

Todo finalizaba por la noche con el baile, el cual se hacía en la posada. Era, sin duda alguna, uno de los bailes más importantes del año debido a la gente que acudía. Los matianeros más mayores recuerdan que era baile suelto con los mismo músicos que tocaban en Las Ánimas, pero los más jóvenes recuerdan cómo en los años 60 ya se había introducido la música de tocadiscos y el baile suelto con los músicos del lugar se reservaba sobre todo para los domingos en las casas y para la Navidad.

La vida en Matián y todas sus manifestaciones culturales se truncó en la década de 1960, cuando en una década escasa la aldea quedó prácticamente despoblada en uno de los claros ejemplos de éxodo rural hacia zonas industrializadas (Valero Escandell 1994, 1999).

En la actualidad y de unos años a esta parte se ha vuelto a retomar la celebración del día de san Antonio en Matián, el fin de semana más próximo al 13 de junio. Desde Ibi, Marcos Galera Reche y Ana Martínez organizan un autobús para aquellos matianeros emigrados que quieren asistir a la celebración. Miguel Azor Lizarte, Juan Martínez Azor y Antonia Galera Reche, algunos de los pocos matianeros que tienen casa en el lugar, organizan el día con la colaboración del Ayuntamiento de Cúllar, que consiste en una misa en la ermita, procesión por la cortijada y una comida en la posada a la que se invita a los asistentes.

\subsubsection{La representación de moros y cristianos}

Según Rosa Galera Reche, nacida en la década de 1920 y cuyo padre, el tío Constante, fue encargado, guarda y alcalde pedáneo de la aldea después de la Guerra Civil, la representación ya se celebraba con anterioridad a esta, se paró durante la contienda y se retomó después hasta finales de la década de 1950, cuando hubo un par de años en que dejó de celebrarse. Según el testimonio de Gregoria Fernández Carrión, que participó en la última representación, esta se realizó en 1962. Sin duda alguna, la emigración hacía Ibi que empezó en 1963 ya había empezado a hacer mella entre los más jóvenes, que empezaban a salir de la aldea a buscar trabajo y un futuro mejor.

En cuanto al origen de la representación, hay que decir que este tipo de textos solían transmitirse por vía oral hasta que en algún momento determinado alguna persona decidía escribirlos en papel para hacerlos perdurar con el paso de los años. En algunos casos, en ese proceso dicha persona solía modificar y adaptar los textos de tradición oral adaptándolos a su gusto, bebiendo de la tradición de lugares próximos o añadiendo partes de nueva creación dando como resultado una obra única.

Para averiguar el origen del texto matianero, por vía oral Marcos Galera Reche explica que "el 
manuscrito que se conserva en la actualidad fue escrito por mí de otro que se encontraba en mal estado realizado por José Martínez Reche, el Platero, con la ayuda de su hermana Dionisia, la cual era maestra, por entonces, en Matián". Según dicho informante, él realizó una copia sin modificación alguna del documento que se conservaba por estar el anterior en mal estado, y dicha copia se realizó en 1954.

José Martínez Reche era natural de El Contador, una pedanía de Chirivel situada en el límite de las provincias de Almería y Granada, y tenía bastante relación con Matián, puesto que su hermana era maestra en el lugar e iba habitualmente a visitarla, además de tener allí familia. Antonio Martínez, su hijo, cuenta que "el amor hacia la lectura y la escritura de mi padre lo llevó a recoger numerosas leyendas, cuentos y relatos interesándose por las tradiciones, en general de las aldeas cercanas a las suyas y a crear multitud de poesías. En cuanto a la representación de Matián, recuerdo ir de niño [después de la Guerra Civil] con mis padres y de ser muchos de sus versos muy parecidos a los de El Contador, ya que yo salí de ángel en mi pueblo".

Por desgracia, la representación de moros y cristianos de El Contador no se conserva en la actualidad y nos resulta imposible compararla con la de Matián. Sin embargo, dada la afición por la poesía de José Martínez Reche y la afirmación de su hijo, entendemos que él sí que llevó a cabo alguna modificación en la copia que realizaría y que posteriormente copiaría de nuevo Marcos Galera Reche en 1954. Dicha teoría la corroboraremos más adelante con el análisis del texto propiamente dicho.

En cuanto a la preparación de la representación, los testimonios orales recuerdan que quien se encargaba de organizarla era Lorenzo Miras, el tío Lorenzo el del Molino, al que llamaban el director o apuntador. Como hemos apuntado en el apartado 2.1., el tío Lorenzo desempeñaba el papel de Mayordomo y se encargaba también de convocar la Cuadrilla de Ánimas en el ciclo festivo de la Navidad. El tío Lorenzo convocaba a los papelistas en su casa del molino, a unos $2 \mathrm{~km}$ de Matián, durante los meses anteriores a la fiesta; una vez que terminaban con las labores del campo o del hogar se juntaban allí para aprenderse y ensayar la representación. Algunos de los actores que, con ilusión, constancia y capacidad, escenificaban "los papeles" fueron, según los testimonios orales, Pedro López (abanderado), su hija María (cantinera cristiana), José Motos (general cristiano), su mujer Antonia Galera Reche, su hermano Marcos Galera Reche (embajador moro), Antonio Miras, hijo del tío Lorenzo (general moro), su hermana María Miras, José Cuevas (embajador moro), el tío Benito Carrión (espía moro y otros años Luzbel, el diablo), Gregorio Pozo, Gregoria Fernández Carrión (cantinera mora) y su hermano Joaquín (ángel de la guarda), entre otros.

Los trajes que se utilizaban en la representación estaban confeccionados por los propios matianeros utilizando ropa de la mili, refajos, mantas y telas, a veces prestados. A principios de la década de 1950 se confeccionaron unos más elaborados que se llevaron a una sastrería de Cúllar, pero desafortunadamente no se conservan en la actualidad. El papel de Luzbel o diablo se solía pintar la cara y llevaba una cuerda a modo de rabo. En los enfrentamientos entre los dos bandos se utilizaban espadas del ejército para las luchas y, en algunas ocasiones, los espías llevaban unas de madera.

Hoy en día solo nos queda el recuerdo de los moros y cristianos en la memoria y en las fotografías conservadas por los matianeros como señal de identidad de lo que fueron y donde vivieron, sintiéndose orgullosos de su pasado y trasmitiéndoselo a sus futuras generaciones.

\subsection{Análisis y estudio sobre la representación de moros y cristianos a san Antonio en Matián}

Como hemos apuntado anteriormente, el manuscrito que se conserva en la actualidad está en posesión de Antonia Galera Reche, hija del antiguo guarda de Matián, el tío Constante, y propietaria de la posada. A modo anecdótico, se encuentra dentro de una carpeta fechada en 1915, aunque el texto fue copiado el 11 de junio de 1954 por Marcos Galera Reche, su hermano, de otro anterior y desaparecido escrito por el 
La representación cuenta con dos partes: la primera, con 780 versos y que se representaba por la mañana, y la segunda, con 675 y que se representaba por la tarde. Seguidamente, ofrecemos un resumen del argumento.

\subsubsection{Argumento de la representación}

\section{Primera parte}

Almanzor, general moro, entrega a Muley, su embajador, una carta que debe entregar a Gonzalo, general cristiano, en la que pide a los cristianos que se vayan de Matián. Gonzalo no lo acepta y les declara la guerra. Entonces, ordena a su espía que controle los movimientos de los moros y a Talismán, su embajador, que revise los escuadrones y que los coloque en puntos estratégicos, encomendándose él y sus tropas a san Antonio como patrón de la aldea.

Muley, el embajador moro, vuelve a presentarse ante los cristianos solicitándoles el santo y la retirada de la plaza en un acto que desemboca en la discusión entre embajadores. Gonzalo, lleno de cólera, hace jurar a sus soldados combatir en la guerra declarada, mientras que Maumet, espía moro, se dirige a su capitán, Almanzor, para que prepare las tropas.

Una vez formados todos, Almanzor se dirige a Gonzalo insistiéndole en su retirada, entrega del santo y su conversión al islam. Este no lo acepta y comienzan una lucha en la Gonzalo termina rindiéndose. Almanzor solicita un duro rescate por la imagen del santo y Gonzalo lo acepta diciéndole que le entregará la cantidad correspondiente por la tarde, a las tres.

\section{Segunda parte}

Mientras descansan esperando la hora señalada para la entrega del rescate del santo, Almanzor, general moro, solicita a Muley, su embajador, que controle las tropas moras para que se encuentren siempre preparadas. Retrasándose a la hora acordada, Gonzalo y Talismán, general y embajador cristianos, llegan al lugar y piden a los moros que se conviertan al cristianismo.

Almanzor no lo acepta y, dispuesto a combatir, pide la ayuda sobrenatural de Luzbel, el diablo, con el que hace un pacto entregándole su alma y la de sus soldados a cambio de salir victoriosos. Gonzalo, en cambio, se encomienda a san Antonio pidiéndole fuerza, valor y poder celestial, el cual le llega por medio del Ángel de la Guarda.

El ángel derrota a Luzbel y sus intenciones arrojándolo al abismo mientras que Gonzalo le habla a Almanzor de María, la madre de Jesús y de su virginidad e inmaculada concepción. Almanzor no acepta el credo cristiano y le declara combate, en el cual cae rendido y solicita su bautismo. Muley, el embajador moro, no admite la derrota y pelea con Talismán, el embajador cristiano, pero también cae derrotado y adopta el cristianismo.

La cantinera cristiana, que en todo momento ha estado animando a su general y a su embajador, convence a la cantinera mora, que ha hecho lo mismo con los suyos, para que se convierta al cristianismo. Finalmente, todos los moros aceptan la religión cristiana y los cristianos los aceptan como hermanos. Talismán finaliza la representación reconociendo la voluntad de Dios, dando gracias y pidiéndole la bendición a san Antonio.

\subsubsection{Análisis general de la representación}


Para caracterizar la representación e intentar fijar un origen realizaremos dos tipos de análisis. En primer lugar la estudiaremos como texto individual y seguidamente la compararemos con otras representaciones de la zona para ver hasta qué punto la han influenciado.

Los personajes, según aparecen nombrados en la representación, son:

General moro: Almanzor.

Embajador moro: Muley.

Espía moro: Maumet.

General cristiano: Gonzalo.

Embajador cristiano: Talismán.

Espía cristiano.

Cantinera mora.

Cantinera cristiana.

Abanderado.

Luzbel.

Ángel de la guarda.

En la tradición oral de los matianeros, sin embargo, a los generales moro y cristiano se les conoce como rey moro y rey cristiano. Hay que destacar también de esta representación que se produce la intervención sobrenatural de Luzbel (diablo en la tradición oral) y del ángel, simbolizado éste último como el de la guarda, así como la presencia de dos personajes femeninos (cantinera cristiana y cantinera mora), característica que hace de esta obra especial, pues era poco usual la presencia de mujeres en las representaciones de moros y cristianos. Se tiene constancia de que en la representación de moros y cristianos de las pedanías de El Ogarite y Los Álamos (Oria), relativamente cercanas, así como Somontín dentro del Valle del Almanzora, también existe esa figura femenina, por lo que la localización y la comparación futura con dicho texto podría aportar datos interesantes.

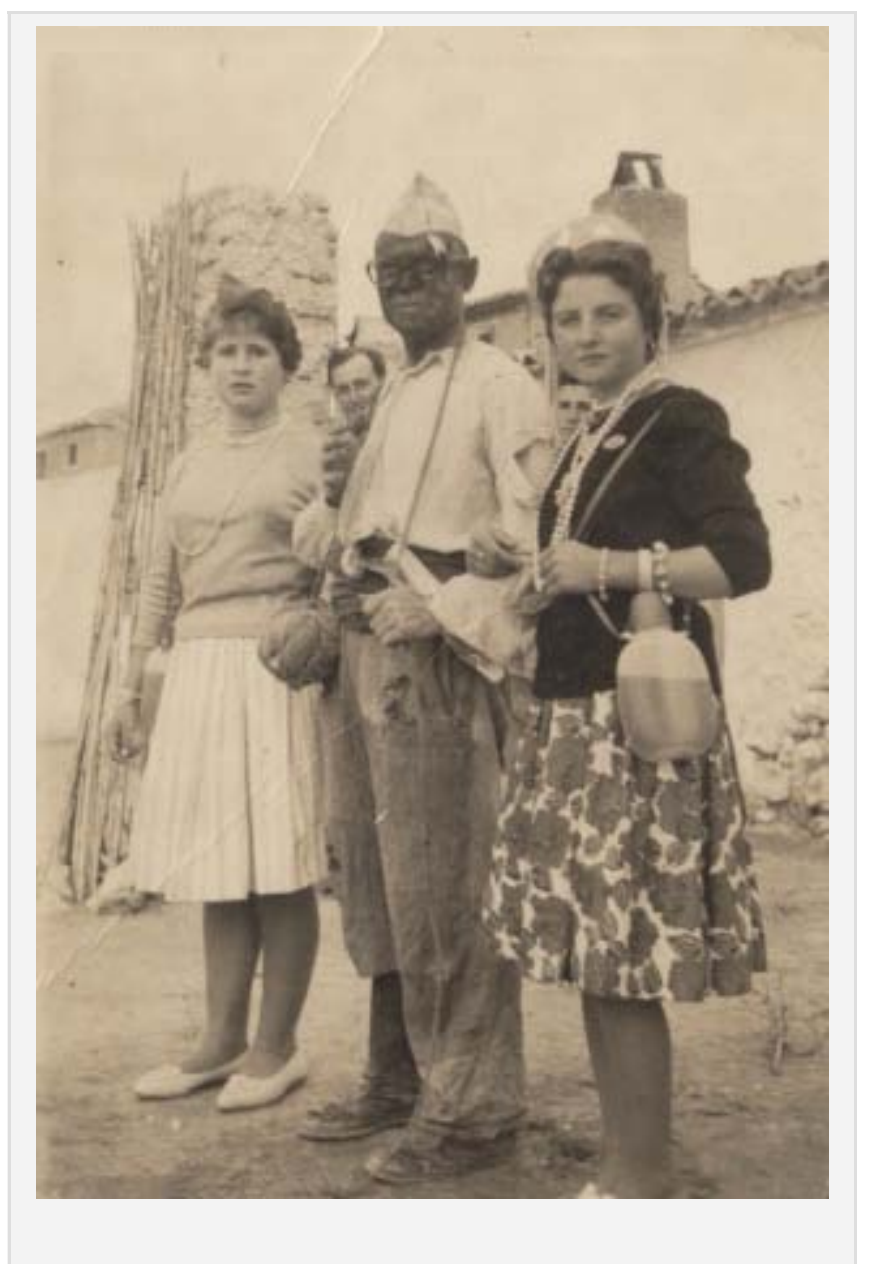


Por otro lado, destaca el romance como estructura métrica, aunque también utiliza otro tipo de estrofas, como por ejemplo, la redondilla:

\title{
Gonzalo:
}

\author{
Por él la prosperidad \\ hace que al rico le sobre \\ y que parta con el pobre \\ el pan de la caridad.
}

En cuanto al lenguaje utilizado, encontramos palabras propias de finales del siglo XIX, frases bélicas y guerreras, así como sentencias militares propias de este tipo de relatos donde se produce un enfrentamiento entre moros y cristianos:

\section{Gonzalo:}

Revisa los escuadrones, en el cerro del Almirez

me colocas cien cañones con mil ametralladoras que guarden los batallones.

A modo de ejemplo, las primeras ametralladoras aparecen en 1861 por Gatling y en 1884 por Hiram Maxim, por lo que la inclusión de dicho término delata un origen o modificación posterior a esas fechas.

Como hemos comentado en el apartado 3, el Romanticismo trae consigo a finales del siglo XIX un amor hacia las tradiciones caballerescas y un ensalzamiento del patriotismo tal y como se refleja en estos versos:

\section{Gonzalo:}
¿Has perdido la memoria de nuestro valor pasado? Examina bien la historia y en ella está consignada su valor y nuestra gloria, pues el valor castellano nunca domó fuerza alguna, ni el fenicio, ni el romano, ni el francés, ni el mahometano.

Se tiene constancia de numerosas obras literarias y teatrales que nacieron tras la victoria de España sobre Marruecos en la llamada Guerra de África de 1860, como es el caso de La toma de Tetuán, drama patriótico en tres actos y en verso, original de Antonio Enrique de Zafra o Un soldado voluntario, la toma de Tetuán de Juan Landa. Estas representaciones no solo se escenificaron en España, sino también en otros países hispanoamericanos.

Durante este período, pequeñas localidades como Benínar, en la Alpujarra, retomaron sus fiestas de moros y cristianos, ya que venían muy a propósito con lo que se quería ensalzar (Díaz Baños et al. 2011), y hubo otras en las que se crearon desde cero o en las que se adoptaron la representaciones de pueblos cercanos que ya las celebraban, adaptándolas normalmente algún letrado local a su contexto 
específico.

Creemos que ese podría ser el caso de la representación de Matián, ya que demuestra una clara influencia de la guerra de África: Tánger se sitúa como ciudad de donde parte Almanzor, el general moro, lo cual nos hace situar el origen de la representación con posterioridad a este hecho histórico.

También se observa la adaptación al lugar, ya que aparecen hasta 20 topónimos entre accidentes geográficos, caminos o nombres de cortijos o aldeas (12). Esto también ocurre en las representaciones primitivas de Benamaurel y Zújar, las de Pozo Iglesias, entre otras, lo que hace pensar que su autor tenía un claro conocimiento de la aldea:

Luzbel:

y el cerro del Almirez.

Colocas cien cañones

de artillería sencilla,

destruyes los pabellones

del Saúco, la Bermeja (orig. Mermeja)

el cortijo de la Pililla.

Se observa también que se añadieron o adaptaron versos de acuerdo con los habitantes de la zona:

\section{Gonzalo:}

También el del cementerio

lo has de tener cercado,

no sea que Gregorio Pozo

nos entre del Colorado.

(...) El de la Casa del Abad, (orig. Casa lavá)

ahí me tienes que poner

cien piezas de artillería

porque Lorenzo y Paulino

viven de la pillería.

Espía:

Desde allí pasé a Pulpite,

casa el Regalao vi cuatro,

casa del Rambla vi quince,

y doscientos casa el Gato.

Casa de Ramón Perico ochocientos,

casa de Pepe Burgos mil

y otros tantos más abajo.

Y en la casa de Fernando

no han querido alojarlos

y Pepa la de Vicente

también los ha despachado.

Según el testimonio de Pilar Fernández Reche, que a fecha de hoy cuenta con 91 años, el Lorenzo que se nombra era cuñado del tío Lorenzo el del Molino, apuntador o director de la obra, y vivía en la Casa del Abad después de la Guerra Civil, al igual que Paulino, que era yerno del antiguo guarda de Matián. En cuanto a los nombres de pulpiteros, también se refieren a gente conocida en Matián en la década de 1940-50: Ramón el Regalao, guarda de la aldea; Andrés el Rambla, Pepe Burgos; Fernando, que tenía una posada; o Pepa, mujer de Vicente Vigueras e hija del tío José Reche, antiguo propietario de una 
casa en Matián.

Probablemente, dichos versos serían escritos en los años de posguerra con el fin de hacer la representación más cercana a los vecinos de la aldea y su autor sería seguramente José Martínez Reche, el Platero, con la ayuda de su hermana Dionisia, maestra de Matián, y quizá de algún otro matianero implicado en las fiestas como el tío Lorenzo el del Molino.

La parte jocosa y picaresca -característica de las representaciones de Andalucía- viene dada, principalmente, por los espías:

Espía:

Salí del Saúco huyendo para el cortijo de don Pablo, (orig. Lompablo)

allí fue el susto más grande

al ver que estaban meando

las mujeres del cortijo

echando unos chorros tan largos

que las corrientes me llevaron.

¡De los orines les hablo!

Es interesante observar el ingenio del autor de este pasaje, ya que sitúa la parte más bronca en el cortijo de Don Pablo, en la zona perteneciente a la aldea de Pozo Iglesias, lejos de Matián, quizá para evitar situarla en otro lugar más cercano cuyos habitantes pudieran asistir a la representación y sentirse ofendidos.

En otro orden de cosas y a modo de anécdota, se introduce el tipo de sociedad de los matianeros y su manera de vivir, tal y como comprobamos en los siguientes versos donde Gonzalo, general cristiano, habla de san Antonio y su importancia entre los vecinos de Matián:

\section{Gonzalo:}

Por él la prosperidad hace que al rico le sobre y que parte con el pobre el pan de la caridad.

Pasando a la segunda parte del análisis y comparando esta representación con otras de la zona, se observa una clara influencia de los textos primitivos de Benamaurel o de la adaptación realizada en 1898 de estos para la representación de Cúllar en honor a nuestra señora de la Cabeza, tal y como comprobamos, por ejemplo, en los versos del ángel al terminar la primera parte:

\section{Benamaurel}

No te aflijas buen cristiano, que Dios oyó tus lamentos y por la gracia de su Madre me manda en estos momentos a que te brinde mi mano y ampare tus desalientes.

Cúllar

No te aflijas, buen cristiano que Dios oye tus lamentos, 
No te aflijas buen cristiano que del cielo soy mandado para que te dé la mano y que me ponga a tu lado. Dios oyó tu petición y me ha mandado al momento.

Sin embargo, si comparamos la matianera con el auto sacramental Cautiverio y rescate de nuestra señora de la Cabeza que se escenifica actualmente tanto en Benamaurel como en Zújar, existe también una semejanza de ciertos actos de la representación de Matián con la realizada en estas localidades, especialmente la de Benamaurel.

Teniendo en cuenta la importancia de las fiestas de moros y cristianos de Zújar y Benamaurel a lo largo de los siglos, especialmente en el siglo XIX y principios del XX -recogidas por numerosos escritores en sus viajes o ensayos históricos (13)- pensamos que el autor de la representación, seguramente un letrado local, las debía de conocer y debió de asistir de manera personal, ya que Matián se encuentra relativamente cerca de dichas poblaciones. Es así que encontramos cierto parecido en cuanto al contenido de la representación especialmente en:

\begin{tabular}{|l|l|}
\hline \multicolumn{1}{|c|}{ Representación de Matián } & \multicolumn{1}{|c|}{$\begin{array}{c}\text { Cautiverio y rescate de nuestra señora de la } \\
\text { Cabeza de Benamaurel y Zújar }\end{array}$} \\
\hline Pacto con el diablo de Almanzor & Pacto con el diablo de Celín \\
\hline Juramento de soldados cristianos & Juramento de soldados cristianos (solo en Benamaurel) \\
\hline $\begin{array}{l}\text { Hora de quedar al siguiente día o por la la } \\
\text { tarde: tres de la tarde }\end{array}$ & $\begin{array}{l}\text { Hora de quedar al siguiente día o por la tarde: las tres de la tarde } \\
\text { (solo en Benamaurel) }\end{array}$ \\
\hline Diálogo entre Ángel y Luzbel (lucha) & Diálogo entre Ángel y Luzbel (lucha) \\
\hline
\end{tabular}

Para finalizar el análisis, hay que decir que las representaciones de moros y cristianos en líneas generales tienen un sentido religioso, ya que se hacen para honrar a una sagrada imagen; guerrero, puesto que se lucha para tomar un castillo o pueblo y rescatar la imagen; apostólico, debido a que se habla de la importancia de la religión cristiano-católica y del bautismo; y, en muchas ocasiones, patriótico, como es el caso.

Desde un punto de vista religioso, en la representación aparecen versos en los que se hace referencia a la virginidad e inmaculada concepción de la Virgen María (14), la aceptación del libro sagrado y el nacimiento, pasión y resurrección de Jesús, como dogmas de fe.

Aunque el moro acepta el bautismo (supremacía del cristianismo frente a la religión islámica), se remarca la bondad cristiana, que acepta a los conversos como hermanos.

\section{Conclusiones}

Tal y como argumentan Albert-Llorca y González (2003) las embajadas son textos que apuntan, en términos grandilocuentes, la nobleza y el valor de los cristianos y los motivos de compromiso en la 
batalla: defender la patria y la fe verdadera.

La embajada o representación de Matián cumple con estos cánones y se enmarca en las representaciones andaluzas, con una parte jocosa y de picaresca expresada por los espías, cuya función era divertir y acercar el contenido de la obra con un humor más bronco y con escenas paródicas por medio de lugares típicos y anécdotas locales.

De acuerdo con el análisis realizado, creemos que debió de ser escrita por algún letrado local con posterioridad a la Guerra de África (1859-1860), a finales del siglo XIX o primeras décadas del XX, bebiendo de representaciones cercanas como la de Cúllar, que en 1898 adaptó el texto primitivo de Benamaurel para su celebración en honor a nuestra señora de la Cabeza. Sin embargo, también debió basarse en el texto que actualmente se representa en Zújar y Benamaurel, Cautiverio y rescate de nuestra señora de la Cabeza, ya que hay claras semejanzas en cuanto a partes de su contenido y modo de desarrollarlo con escenas parecidas de dicho auto sacramental.

Las fuentes orales nos confirman que el texto experimentó una última modificación en los años de posguerra realizada por José Martínez, el Platero, y su hermana Dionisia, maestra de Matián, con la intención de hacerla más cercana a los vecinos de la aldea. Sería interesante hallar, si existe y se encuentra escrita, la representación anterior a la Guerra Civil. Finalmente, la última copia realizada se hizo en 1954 por Marcos Galera Reche, la cual se conservada por su hermana Antonia en buenas condiciones a la actualidad.

La sociedad que representaba el texto era la puramente rural propia del Altiplano de Granada a mediados de siglo $X X$, sumida en un falta de servicios y de posibilidades de ascenso social debido al latifundio y la relación de aparecería en la que vivían casi todos sus habitantes. Ello hizo que la representación se realizara por última vez en 1962, justo antes de que empezara la cadena migratoria que propició el éxodo en masa de los habitantes de Matián hacia Ibi (Alicante), donde residen la mayoría de ellos en la actualidad.

\section{Notas}

1. Información proporcionada a Cristóbal Cabeza-Cáceres por Javier Castillo Fernández, a quien agradece su aportación.

2. Documentación histórica localizada por Adrián Castillo Fernández en el Archivo Histórico de Cúllar, consultable en su blog Tierra de Cúllar: http://tierradecullar.blogspot.com.es/2011/05/cartanombramiento-de-alcaldes-cullar.html

3. Información proporcionada por la parroquia de Cúllar, donde se encuentran los libros sacramentales de Matián hasta el año 1966.

4. Las representaciones de moros y cristianos han sido estudiadas, analizadas y recogidas en Martínez Pozo (2008: 112-330 y 2009a: 139-258).

5. El análisis de estas representaciones se puede consultar en Martínez Pozo (2008: 119-131, 241-311).

6. La evolución histórica de ambas poblaciones entorno a la Virgen de la Cabeza se ha estudiado por numerosos investigadores desde un punto de vista histórico, cultural, religioso y antropológico, entre los que destacamos a Arredondo Arredondo (2007), Magaña Visbal (1926), Martínez Pozo (2008-2009), Muñoz Renedo (1972) y Peñalver Navarro (2008). 
7. Se recomienda para su conocimiento, los estudios realizados por Muñoz Renedo (1972), Brisset Martín (1988) y Arredondo Arredondo (2007), así como la colección de Martínez Pozo, donde puede consultarse su evolución histórica, análisis, argumento y la lectura completa de la representación.

8. Es necesario leer para su entendimiento y comprensión el pregón de fiestas de Francisco Aznar Lara, recogido en Martínez Pozo (2009: 84-88), así como las palabras de Francisco Arredondo Garrido en Martínez Pozo (2009: 87).

9. Juan de Dios Villanueva Roa, estuvo de maestro de la escuela de adultos en Cúllar. Gracias a su iniciativa, la representación de Cúllar salió a la luz habiendo sido conservada por una familia a la que Martínez Pozo le agradece su amistad y apoyo a lo largo de estos años.

10. Las fiestas de moros y cristianos en honor a nuestra señora de la Cabeza junto con la representación en honor a san Sebastián en Cúllar, así como los documentos y manuscritos hallados sobre esta, puede ser consultados en la colección realizada por Martínez Pozo sobre las fiestas de moros y cristianos en la Comarca de Baza.

11. La representación de Pozo Iglesias ha sido citada, en líneas generales, por Martínez Pozo (2009: 258) y analizados algunos de sus aspectos brevemente por Torres Jaraba (2010: 74-84).

12. En el siguiente enlace se puede consultar un mapa con dichos topónimos: https://maps.google.com/maps/ms?

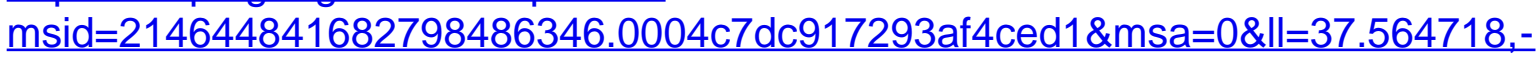

$2.466602 \&$ spn $=0.090623,0.181789$

13. La documentación existente sobre la devoción a la Virgen de la Cabeza y la relación con las fiestas de moros y cristianos en Benamaurel y Zújar a lo largo de los siglos se puede consultar en la colección de Martínez Pozo siendo de gran interés para conocer y comprender estas fiestas en el antiguo Reino de Granada.

14. Sobre las conexiones literario-religiosas de este tipo de textos, véase Brisset (1988).

\section{Bibliografía}

Albert-Llorca, M. (y J. A. González Alcantud)

2003 Moros y cristianos: representación del otro en las fiestas del mediterráneo occidental. Granada, Diputación de Granada, Centro de Investigaciones Etnológicas Ángel Ganivet.

Andújar Castillo, Francisco (y Domingo Marcos Giménez Carrillo)

2011 "Iglesia, negocios y poder entre América, Madrid y el Reino de Granada en el siglo XVII: Bartolomé Marín de Poveda", en Francisco Andújar Castillo y Domingo Marcos Giménez Carrillo (eds.), Riqueza, poder y nobleza: Ios Marín de Poveda, una historia familiar del siglo XVII vista desde España y Chile. Almería, Editorial Universidad de Almería: 179-212.

Archivo General de Andalucía, fondo Zapata, signatura 4973.2. Fols. 38-141. Cortixada de Mathian: http://memoriaoraldematian.wordpress.com/2012/06/09/la-fiestas-de-matian-san-antonio-los-moros-ycristianos-y-el-baile/

Archivo General de Simancas, Catastro de Ensenada, Respuestas Generales, libro 281, folio 121: 
Arredondo Arredondo, Francisco

2007 Fiestas de Zújar en honor a nuestra señora de la Cabeza. La representación de moros y cristianos.

Baza, Excmo. Ayuntamiento de Zújar.

Brisset Martín, Demetrio

1988 Fiestas de moros y cristianos en Granada. Granada, Diputación Provincial.

Castillo Fernández, Javier

1996 "Teatro popular. Análisis de los textos de las representaciones de moros y cristianos de Cúllar (Granada)", Demófilo, n 18. Sevilla, Fundación Machado: 93-110.

2008 "Balance de la recuperación de la fiesta de moros y cristianos de Cúllar (Granada) (1983-2008)", en Modesto García Jiménez (coord.), Música de tradición oral. XXV Años de los encuentros de cuadrillas de ánimas de Los Vélez. Almería, Instituto de Estudios Almerienses, 299-318.

Díaz Sánchez, J. A.

2012 "La fiesta en el altiplano de Granada", en M. A. Martínez Pozo (coord.), Fiestas de moros y cristianos en España. Huella del milenio del Reino de Granada. Baza, Excmo. Ayuntamiento de Benamaurel y GDR Altiplano de Granada Baza: 504-536.

Domene García, Julián (y José Ignacio Rojas Sola)

2001 "Estudio histórico de los molinos harineros en el altiplano de Baza", en Actas de las III Jornadas Nacionales de Molinología. Murcia, Consejería de Educación y Cultura de la Región de Murcia, 221-226.

Fernández Hervás, E.

1992 Las fiestas de moros y cristianos en España y su estudio en la provincia de Jaén. Jaén, Edición del autor.

García Gea, José

2010 Chirivel, Cúllar, Oria y Los Vélez: una mirada al pasado. Lorca, Edición del autor.

Gómez García, Pedro

1992 "Análisis de las antiguas «Relaciones de moros y cristianos de Laroles (La Alpujarra)»", Gazeta de Antropología, n 9, artículo 08:

http://www.gazeta-antropologia.es/?p=3680

http://hdl.handle.net/10481/13661

Jaramillo Cervilla, Manuel

2005 "Evolución de la religiosidad en Cúllar y nuestros pueblos. Las fiestas de moros y cristianos", Boletín del Centro de Estudios Pedro Suárez: Estudios sobre las comarcas de Guadix, Baza y Huéscar. Guadix, Centro de Estudios Pedro Suárez. Guadix: 77-94.

Magaña Visbal, L.

1926 Reseña histórica sobre la aparición, culto y milagros de nuestra señora de la Cabeza que se venera en la iglesia parroquial de Zújar. Baza, Imprenta Cervantes.

Martínez Pozo, Miguel Ángel

2008 Descubre el origen... Fiestas de moros y cristianos de la comarca de Baza. Benamaurel-CúllarZújar. Baza, Imprenta Cervantes.

2009 En busca de la verdad... Fiestas de moros y cristianos de la comarca de Baza. Nuestra señora de la Cabeza. Baza, Imprenta Cervantes.

2010 Al descubierto... Cúllar, ayer y hoy, ¿pero mañana? Fiestas de moros y cristianos en honor a 
Martínez Pozo, Miguel Ángel (coord.)

2012 Fiestas de moros y cristianos en España. Huella del milenio del Reino de Granada. Baza, Ayuntamiento de Benamaurel y Grupo de Desarrollo Rural del Altiplano de Granada.

Muñoz Renedo, Carmen

1972 La representación de moros y cristianos de Zújar. Cautiverio y rescate de nuestra señora de la Cabeza. Madrid, Instituto Miguel de Cervantes. Departamento de Dialectología y Tradiciones Populares.

Peñalver Navarro, Carmen

2008 Cautiverio y rescate de nuestra señora de la Cabeza. Fiesta de moros y cristianos de Benamaurel. Hermandad e insignias de nuestra señora de la Cabeza. Baza, Imprenta Cervantes.

Ruiz Baños, R. (F. F. Maldonado Calvache y R. Bailón Moreno)

2011 "Los moros y cristianos de Benínar en 1860", Farua, n 14. Berja, Centro Virgitano de Estudios Históricos: 59-80.

Tomás Loba, Emilio del Carmelo

2008 "Etnografía musical en los rituales religiosos festivos de Los Vélez", en Modesto García Jiménez (coord.), Música de tradición oral. XXV Años de los encuentros de cuadrillas de ánimas de Los Vélez. Almería, Instituto de Estudios Almerienses, 33-80.

Torices Abarca, Nicolás (y Eduardo Zorita Povedano)

1994 Inventario cortijos, haciendas y lagares. Provincia de Granada. Matián. Sevilla, Junta de Andalucía, Consejería de Vivienda y Ordenación del Territorio:

http://www.iaph.es/patrimonio-inmueble-andalucia/resumen.do?id=i171330

Torres Jaraba, Asunción

2010 Cúllar, ayer y hoy. Fiestas de moros y cristianos en honor a la Virgen de la Cabeza. Baza, Ayuntamiento de Cúllar, Concejalía de Cultura.

Valero Escandell, José Ramón

1994 "De Matián a Ibi: el éxodo masivo de una aldea del norte de Granada", ponencia presentada en $I V$ Jornadas Historia y Fuentes Orales. Historia y memoria del franquismo, 1936-1978. Ávila, 2830/10/1994.

1999 "Matián, 1965-1975: el abandono de una aldea", en Manuel González Portilla y Karmele Zarraga Sangróniz (coord.), IV Congreso de la Asociación de Demografía Histórica (1995). Demografía urbana, migración y envejecimiento. Bilbao, Universidad del País Vasco, 471-484.

Valero Escandell, José Ramón (y Manuel Monleón)

1992 De Matián a Ibi. Documental inédito realizado con una ayuda del Institut Alacantí de Cultura Juan Gil-Albert:

http://youtu.be/q3J3EuT8h9o

Villanueva Roa, Juan de Dios

1987 Fiestas de moros y cristianos en la villa de Cúllar. Festividad de san Sebastián y festividad en honor a nuestra señora santa María de la Cabeza. Baza, Ayuntamiento de Cúllar.

2008. La obra teatral como festejo: Cúllar, una historia, una cultura. Granada, Grupo Editorial Universitario, 2008. 